\title{
Engineering a Highly Defective Stable UiO-66 with Tunable Lewis- Brønsted Acidity: The Role of the Hemilabile Linker
}

\author{
Xiao Feng, Julianna Hajek, Himanshu Sekhar Jena, Guangbo Wang, Savita K.P. Veerapandian, \\ Rino Morent, Nathalie De Geyter, Karen Leyssens, Alexander E.J. Hoffman, Vera Meynen, \\ Carlos Marquez, Dirk E. De Vos, Veronique Van Speybroeck, Karen Leus, and Pascal Van Der Voort*
}

Cite This: J. Am. Chem. Soc. 2020, 142, 3174-3183

Read Online

ACCESS | 네 Metrics \& More | 回 Article Recommendations | sl Supporting Information

ABSTRACT: The stability of metal-organic frameworks (MOFs) typically decreases with an increasing number of defects, limiting the number of defects that can be created and limiting catalytic and other applications. Herein, we use a hemilabile $(\mathrm{Hl})$ linker to create up to a maximum of six defects per cluster in UiO-66. We synthesized hemilabile UiO-66 (Hl-UiO-66) using benzene dicarboxylate (BDC) as linker and 4-sulfonatobenzoate (PSBA) as the hemilabile linker. The PSBA acts not only as a modulator to create defects but also as a coligand that enhances the stability of the resulting defective framework. Furthermore, upon a postsynthetic treatment in $\mathrm{H}_{2} \mathrm{SO}_{4}$, the average number of defects increases to the optimum of six missing BDC linkers per cluster (three per formula unit), leaving the

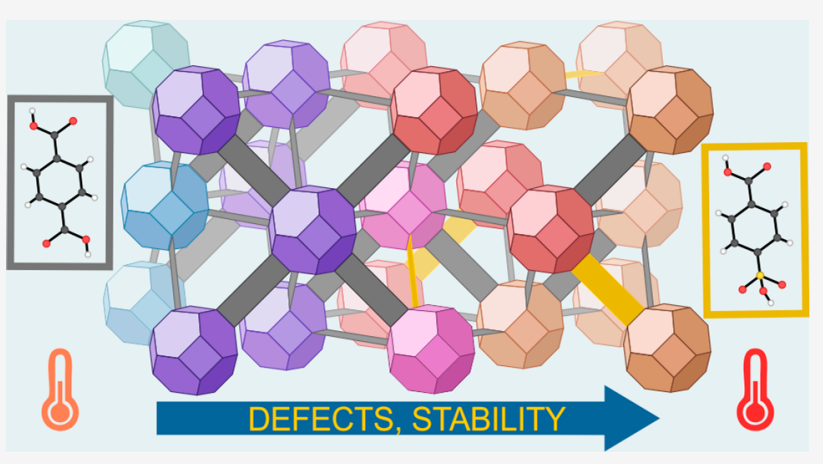
Zr-nodes on average sixfold coordinated. Remarkably, the thermal stability of the materials further increases upon this treatment. Periodic density functional theory calculations confirm that the hemilabile ligands strengthen this highly defective structure by several stabilizing interactions. Finally, the catalytic activity of the obtained materials is evaluated in the acid-catalyzed isomerization of $\alpha$-pinene oxide. This reaction is particularly sensitive to the Brønsted or Lewis acid sites in the catalyst. In comparison to the pristine UiO-66, which mainly possesses Brønsted acid sites, the $\mathrm{Hl}-\mathrm{UiO}-66$ and the postsynthetically treated Hl-UiO-66 structures exhibited a higher Lewis acidity and an enhanced activity and selectivity. This is further explored by $\mathrm{CD}_{3} \mathrm{CN}$ spectroscopic sorption experiments. We have shown that by tuning the number of defects in UiO-66 using PSBA as the hemilabile linker, one can achieve highly defective and stable MOFs and easily control the Brønsted to Lewis acid ratio in the materials and thus their catalytic activity and selectivity.

\section{INTRODUCTION}

$\mathrm{UiO}-66$ is one of the best known metal-organic frameworks (MOFs) due to its outstanding stability, which is caused by the presence of high-valent metal cations creating clusters with high charge densities. ${ }^{1}$ Moreover, UiO-66 is a prototypical MOF in defect engineering because it can bear a high number of defects without loss of structure. ${ }^{2-6}$ In general, the most common approach to create defects is the modulation synthesis approach, in which a large excess of the monocarboxylic acid is used, in combination with the dicarboxylic acid. The monotopic ligands reduce the speed of crystallization and occupy the metal coordination sites to generate defects. The most common modulators used are formic acid, acetic acid, and trifluoroacetic acid, all having a mono coordination mode. ${ }^{3,7-9}$ MOFs with hierarchical porosity have been synthesized using either monocarboxylic acids as modulators or by thermolysis of mixed linker MOFs. ${ }^{10-13}$ In catalysis, the defective UiO-66 (using trifluoroacetic acid as modulator) has already been shown to have a high reactivity in the Meerwein reduction of 4-tert- butylcyclohexanone with isopropanol. ${ }^{14}$ Recently, we used Lproline as a chiral modulator for the synthesis of UiO-type MOF structures which showed an excellent reactivity in the diastereoselective aldol reaction. ${ }^{15}$ Nevertheless, in all cases, the thermal stability of the framework is reduced upon the generation of defects. ${ }^{3,16,17}$ Atzori et al. demonstrated that the maximum number of defects is 4.4 per cluster using benzoic acid in UiO-66. ${ }^{18}$ Bueken et al. reported a similar value of 4.3 missing linkers per cluster. ${ }^{19}$

Apart from monocarboxylic acid modulators, hemilabile ligands can be used in the synthesis of carboxylic MOFs (Figure 1). They have, next to the carboxylate group, a second coordinating functional group (e.g., sulfonate groups). The

Received: December 4, 2019

Published: January 23, 2020 


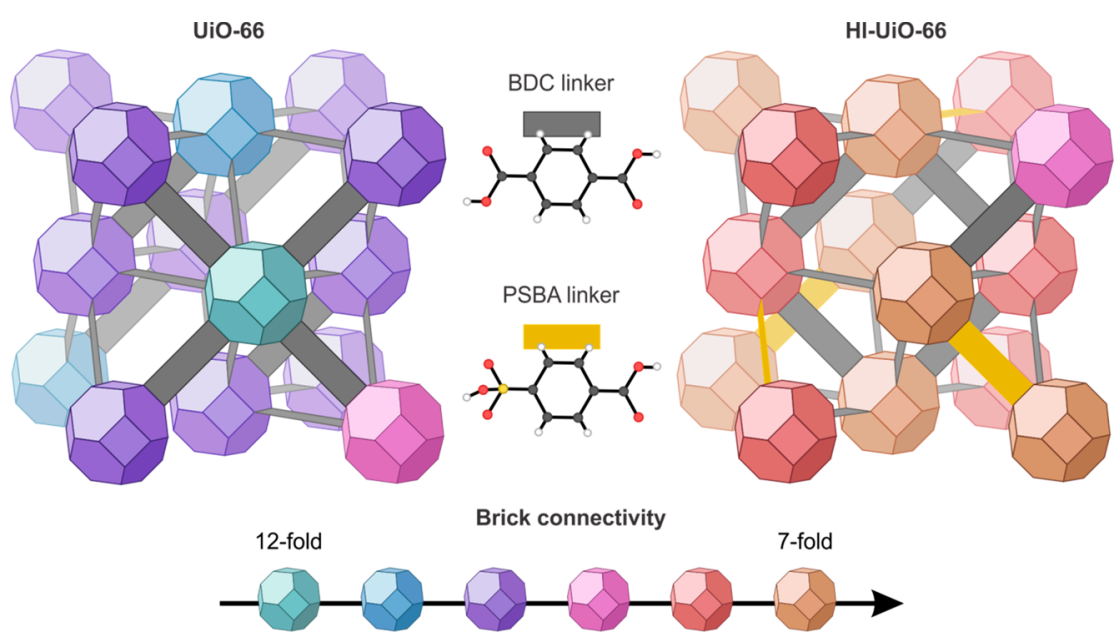

Figure 1. Schematic representation of the UiO-66 and $\mathrm{Hl}-\mathrm{UiO}-66$ materials with possible configurations of the bricks that give rise to coordinatively unsaturated $\mathrm{Zr}$ sites.

concept of the use of hemilabile ligands was introduced by Morris et al. ${ }^{20}$ For example, the hemilabile MOF, denoted as $\mathrm{Cu}-\mathrm{SIP}-3$, prepared by Xiao et al. showed an ultraselective low pressure nitric oxide adsorption upon the reversible phase transformation induced by the change in the coordination of sulfonate group when the water is removed. ${ }^{21} \mathrm{McHugh}$ et al. also demonstrated that a copper paddlewheel MOF exhibited good hydrolytic stability due to the presence of a hemilabile linker. ${ }^{22}$ Until now, hemilabile linkers have only been used to explore the selective gas adsorption, separation, dielectric, and other physical properties of MOFs. ${ }^{20,23,24}$

Herein, we report the synthesis and characterization of hemilabile UiO-66 (Hl-UiO-66) using benzene-1,4-dicarboxylic acid (BDC) and 4-sulfobenzoic acid potassium salt (PSBA) in a $1: 1$ ratio to obtain a highly defective UiO-66 (Figure 1). Because of the inherent weak coordination mode of the sulfonate group, a simple postsynthetic treatment in $\mathrm{H}_{2} \mathrm{SO}_{4}$ was carried out, which resulted in a total of six BDC missing linkers per cluster $\left(\mathrm{Hl}-\mathrm{UiO}-66-\mathrm{SO}_{4}\right)$. This is the theoretical limit to still maintain a three-dimensional UiO-66 network. ${ }^{3,19}$ Importantly, the thermal stabilities of the three MOFs follow the order $\mathrm{UiO}-66<\mathrm{Hl}-\mathrm{UiO}-66<\mathrm{Hl}-\mathrm{UiO}-66-\mathrm{SO}_{4}$, which confirms that the material with the highest number of defects is also the most stable one. The catalytic properties of the obtained materials were evaluated in the isomerization of $\alpha$ pinene oxide, as this reaction allows for discriminating the role of Lewis and Brønsted acid sites. In comparison to the pristine UiO-66 as Brønsted acid catalyst, which showed a moderate activity of $40 \%$ conversion and low selectivity (37\%) at $0.5 \mathrm{~h}$, full conversion and an enhanced selectivity (71\%) is observed for the $\mathrm{Hl}-\mathrm{UiO}-66-\mathrm{SO}_{4}$ materials as Lewis acid catalyst.

\section{EXPERIMENTAL SECTION}

Synthesis of the Hemilabile UiO-66. The synthesis procedure is based on a modified procedure of Biswas et al. ${ }^{25} \mathrm{ZrO}_{2} \mathrm{Cl}_{2} \cdot 8 \mathrm{H}_{2} \mathrm{O}(1 \mathrm{~g}$, $3.1 \mathrm{mmol})$, terephthalic acid $(515 \mathrm{mg}, 3.1 \mathrm{mmol})$ and 4-sulfobenzoic acid potassium salt $(745 \mathrm{mg}, 3.1 \mathrm{mmol})$ were dissolved in a mixture of formic acid $(12 \mathrm{~mL}, 310 \mathrm{mmol})$ and dimethylacetamide $(30 \mathrm{~mL})$ in an ultrasonic bath for $30 \mathrm{~min}$. The resulting mixture was placed in a Teflon-lined autoclave at $150{ }^{\circ} \mathrm{C}$ for $24 \mathrm{~h}$ and subsequently cooled to room temperature. The solid was collected by filtration and washed with dimethylformamide (DMF) and methanol and subsequently stirred in DMF at $70{ }^{\circ} \mathrm{C}(24 \mathrm{~h})$ and methanol under ambient conditions $(24 \mathrm{~h})$ to remove unreacted linker, modulator, and DMF. The final purified product was dried under vacuum at $65{ }^{\circ} \mathrm{C}$.

Postsynthetic Modification (HI-UiO-66-SO ${ }_{4}$ ). Hl-UiO-66- $\mathrm{SO}_{4}$ : $150 \mathrm{mg}$ catalyst was treated in $20 \mathrm{~mL}$ of $\mathrm{H}_{2} \mathrm{SO}_{4}(0.05 \mathrm{M})$. The suspension of the solid was stirred for $24 \mathrm{~h}$ at room temperature. The resulting solid was filtered off and thoroughly washed multiple times with water until neutral $\mathrm{pH}$ was obtained and consequently stirred with methanol for $24 \mathrm{~h}$. The precipitate was filtered and dried under vacuum at $65^{\circ} \mathrm{C}$.

Catalytic Procedure. In a typical catalytic test, $50 \mathrm{mg}$ of catalyst (preactivated for $16 \mathrm{~h}$ at $150{ }^{\circ} \mathrm{C}$ under vacuum) was suspended in 5 $\mathrm{mL}$ of toluene (anhydrous) in a $25 \mathrm{~mL}$ round-bottom flask. Hereafter, $130 \mathrm{mg}$ of $\alpha$-pinene oxide $(0.86 \mathrm{mmol})$ and $146 \mathrm{mg}$ of dodecane $(0.86 \mathrm{mmol})$ as an internal standard were added. This mixture was magnetically stirred at $70{ }^{\circ} \mathrm{C}$. Aliquots were taken from the reaction mixture by syringe at indicated time intervals, filtered with a nylon filter to remove catalyst particles, and diluted with toluene. The products were separated by GC and identified by GC-MS. During a recycling experiment, the catalyst was centrifuged by filtration, washed with toluene and methanol and dried under vacuum at $150{ }^{\circ} \mathrm{C}$ and was then reused. For the filtration tests, the catalyst was filtered off, and the supernatant was reacted further in another vial.

Computational Methodology. All calculations on the two-brick unit cell of studied UiO-66-type materials were performed using the periodic Vienna Ab Initio Simulation Package (VASP code) with the density functional theory (DFT) method to represent the crystal environment. ${ }^{26-30}$ We applied the projector augmented wave (PAW) approach, ${ }^{31}$ and the Brillouin zone was sampled by the $\Gamma$-point at PBE level of theory ${ }^{32}$ including Grimme-D3 dispersion corrections. ${ }^{33,34}$ The kinetic energy cutoff for the plane waves was $700 \mathrm{eV}$; the convergence threshold for the electronic self-consistent field (SCF) calculations was set to $10^{-8} \mathrm{eV}$, and a Gaussian smearing of $0.025 \mathrm{eV}$ was included to improve convergence.

Each equilibrium structure was obtained by performing a fixedvolume geometry optimization at the optimal unit cell volume, which was determined by fitting a Rose-Vinet equation of state ${ }^{35}$ to the electronic energies of seven optimized structures at different unit cell volumes. All geometries were optimized via the conjugate gradient method until the energy difference between subsequent steps became smaller than $10^{-7} \mathrm{eV}$. Hessians were calculated for the optimized structures via a finite difference approach. The corresponding normal modes and vibrational frequencies were obtained after a normal-mode analysis via TAMkin. ${ }^{36}$

\section{RESULTS AND DISCUSSION}

PSBA as a Hemilabile Linker to Create Defects. Synthesis of UiO-66 with hemilabile linkers was carried out 
by varying the ratio of PSBA to BDC (0.2:1, 1:1, and 10:1) and the number of defects was characterized by proton nuclear magnetic resonance $\left({ }^{1} \mathrm{H}\right.$ NMR) of digested MOFs and thermogravimetric (TGA) analysis (Table S1). The material obtained using the $0.2: 1$ ratio has neither PSBA in the structure nor any extra defect corresponding to pristine UiO66 (Figures S1, S3). Using the 10:1 ratio, the obtained material contained a high relative amount of PSBA versus BDC (0.4:1, Figure S2). However, after washing with sulfuric acid, a lower number of defects was obtained (5 defects per cluster, Figure S4). This is probably due to excess of PSBA in the structure, which was removed during the postsynthetic treatment. We noticed a $40 \%$ mass loss after the acid treatment. We found the material obtained by using a 1:1 ratio was the best to retain the number of defects even after acid treatment, which is discussed in detail.

NMR studies were performed to verify the incorporation of PSBA and to determine the experimental molar ratio of PSBA and $\mathrm{BDC}$ in the obtained frameworks after digestion of the samples (Table 1). From these NMR results it was observed

Table 1. Composition and Properties of the UiO-66, Hl$\mathrm{UiO}-66$, and $\mathrm{Hl}-\mathrm{UiO}-66-\mathrm{SO}_{4}$ Materials

\begin{tabular}{|c|c|c|c|}
\hline sample & $\begin{array}{l}\text { initial PSBA: } \mathrm{BDC}^{a} \text { in } \\
\text { reaction mixture }\end{array}$ & $\begin{array}{c}\text { observed } \\
\text { PSBA:BDC }{ }^{b} \text { in the } \\
\text { MOF }\end{array}$ & $\begin{array}{l}\text { number of } \\
\text { defects per } \\
\text { cluster }^{c}\end{array}$ \\
\hline $\mathrm{UiO}-66$ & & & 3.4 \\
\hline $\begin{array}{l}\text { Hl-UiO- } \\
\quad 66\end{array}$ & $1: 1$ & $0.20: 1$ & 4.4 \\
\hline Hl-UiO- & & $0.11: 1$ & 6.0 \\
\hline
\end{tabular}

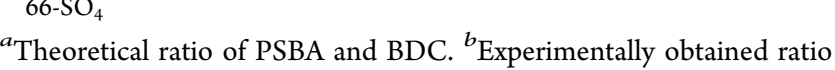
determined by means of NMR. ${ }^{c}$ Number of defects based on TGA and NMR results as described by Shearer et al. ${ }^{3}$

that the molar ratio $\mathrm{PSBA} / \mathrm{BDC}$ in the structure was maintained even after heating the sample up to $400{ }^{\circ} \mathrm{C}$ for $24 \mathrm{~h}$ (Figure S5). This is in contrast to the results observed for monocarboxylic acid based modulators for which a lower decoordination temperature $\left(325{ }^{\circ} \mathrm{C}\right.$ for trifluoroacetate $)$ was obtained. ${ }^{14}$ This suggests that the hemilabile linkers coordinate with both their carboxylate side and their sulfonate side, stabilizing the hemilabile linkers in the structure.

The infrared (IR) spectra show the characteristic bands at $1117\left(\nu_{\mathrm{as}} \mathrm{SO}_{3}\right)$ and $1035\left(\nu_{\mathrm{as}} \mathrm{SO}_{3}\right)$ and $1008\left(\nu_{\mathrm{s}} \mathrm{SO}_{3}\right) \mathrm{cm}^{-1}$ that can be assigned to the asymmetric and symmetric stretching frequencies of sulfonate, respectively, with a slight shift from $1102\left(\nu_{\mathrm{as}} \mathrm{SO}_{3}\right), 1027\left(\nu_{\mathrm{as}} \mathrm{SO}_{3}\right)$, and $1002\left(\nu_{\mathrm{as}} \mathrm{SO}_{3}\right) \mathrm{cm}^{-1}$ of PSBA due to the coordination with the $\mathrm{Zr}$-nodes (Figure S6). ${ }^{37-39}$ The same applies for the peak at $740 \mathrm{~cm}^{-1}$, shifted from 760 $\mathrm{cm}^{-1}$, attributed to the bent $\mathrm{C}-\mathrm{S}$ stretching vibration. These results confirm the coordination of both the carboxylic acid groups of BDC and the sulfonate group of PSBA to $\mathrm{Zr}(\mathrm{IV})$.

To gain further insight on the binding of the sulfonate groups, X-ray photoelectron spectroscopy (XPS) measurements were carried out and analyzed by fitting the respective elements with their binding energy (Figure 2). For PSBA (Ksalt), the deconvoluted $S 2 \mathrm{p}$ peaks at 167.9 and $169.1 \mathrm{eV}$ were attributed to phen- $\mathrm{SO}_{3}{ }^{-}$, coordinated to potassium, while the peaks at 168.7 and $169.9 \mathrm{eV}$ were assigned to hydrolyzed species phen- $\mathrm{SO}_{3} \mathrm{H}^{40,41}$ The $\mathrm{Hl}-\mathrm{UiO}-66$ shows mainly the bands at 168.1 and $169.3 \mathrm{eV}$ (green asterisk), matching with coordinated phen- $\mathrm{SO}_{3}{ }^{-}$in PSBA linker and corroborating the

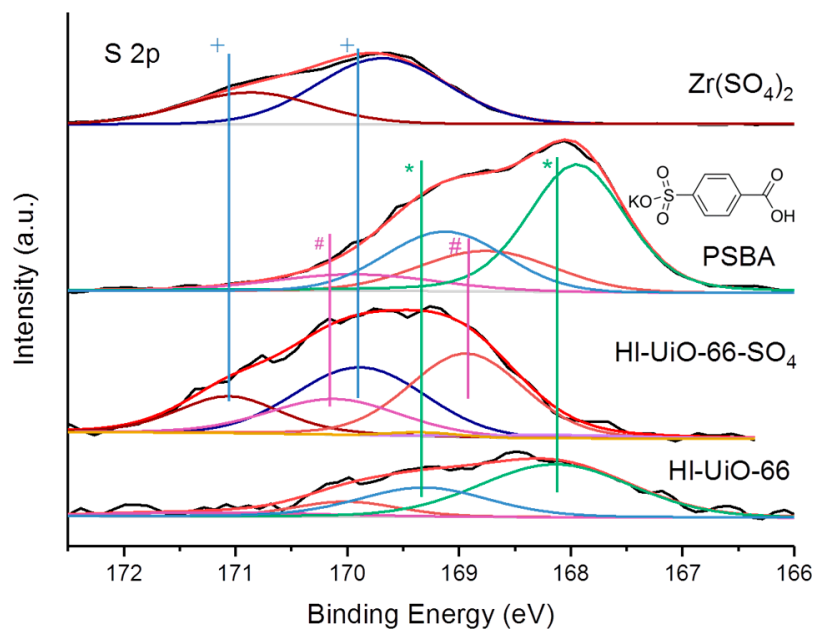

Figure 2. Deconvoluted XPS spectra of Hl-UiO-66, Hl-UiO-66-SO PSBA, and $\mathrm{Zr}\left(\mathrm{SO}_{4}\right)_{2}$, highlighting $\mathrm{S} 2 \mathrm{p}$ element.

coordination of PSBA to zirconium sites and some traces of (free dangling) protonated PSBA linkers.

The crystallinity of the obtained solids was verified by means of powder X-ray diffraction (PXRD) (Figure 3a). An obvious broad diffraction in the $2 \theta$ range between 3 and $7^{\circ}$ was observed in $\mathrm{Hl}-\mathrm{UiO}-66$, originating from the cluster defects. ${ }^{3,42}$ To calculate the number of defects, we performed TGA
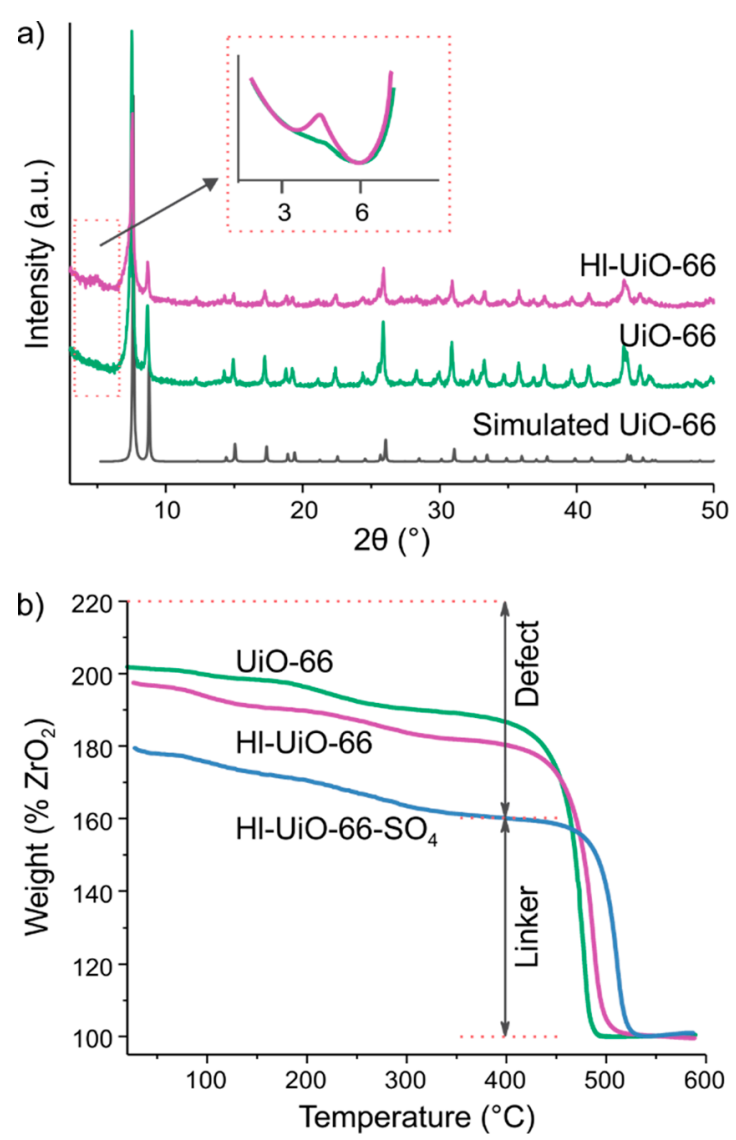

Figure 3. (a) PXRD pattern of the pristine UiO-66 and the HI-UiO66 samples. The inset shows the overlap of PXRD patterns from 3 to $7^{\circ}$ and (b) TGA results obtained of UiO-66, Hl-UiO-66, and Hl-UiO66 washed with $\mathrm{H}_{2} \mathrm{SO}_{4}$ solution. 
analysis, which is one of the most general and efficient methods to study defects in MOFs as the number of defects can be calculated based on the weight loss (Figure 3b). ${ }^{2,3,13,38,41}$ As can be seen from Table 1, on average, the Hl-UiO-66 contains 4.4 defects per cluster. This number is significantly higher than the number of defects present in the pristine UiO-66 using only BDC as linker. This indicates that the PSBA does not only act as a bidentate linker, but also as a modular to create extra defects.

We performed Ar-adsorption for all samples. The logarithmic isotherms are shown in Figure 4. Careful

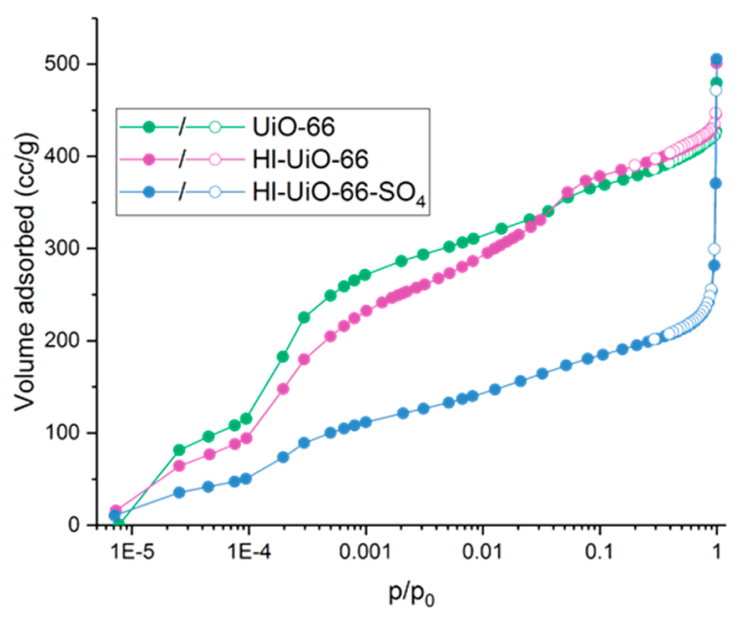

Figure 4. Logarithmic Ar-iostherms for the UiO-66, Hl-UiO-66, and $\mathrm{Hl}-\mathrm{UiO}-66-\mathrm{SO}_{4}$.

inspection of these pristine isotherms shows that the UiO-66 isotherm has two major condensation steps, one at very low pressures (around $1.10^{-5} p / p_{0}$ ) and one at a slightly higher pressure (around $1.10^{-4} p / p_{0}$ ). There is a small increase in uptake as well around $5.10^{-2} p / p_{0}$. These three pores size regions are assigned to respectively the two cages in UiO-66 $(0.8$ and $1.1 \mathrm{~nm})$ and larger micropores (around 1.5-2.0 nm), due to defects. The Hl-UiO-66 shows a decrease in Ar-uptake in the two smaller pore size areas but a very noticeable and significant increase in Ar-uptake around 1.5-2.0 nm. This strongly suggests that the number of larger micropores has increased in the Hl-UiO-66. The pore size distribution, based upon a silica/zeolite kernel, is shown in the Supporting Information (Figures S14-S16).

The energy dispersive X-ray spectroscopy (EDS) mapping of Hl-UiO-66 confirmed that the $S$ species are uniformly distributed inside MOFs (Figure S9), confirming that the PSBA linkers are homogeneously distributed in the materials.

Postsynthetic Modification with Sulfuric Acid and a Remarkable Increase in Stability. Sulfonates have a coordination strength to the $\mathrm{Zr}_{6}$ clusters that is weaker than that of carboxylates. ${ }^{23}$ Therefore, it is comparatively easier to replace the weaker coordinating ligands by a stronger one. In this regard, Hl-UiO-66 was immersed in an acid solution to partially remove the PSBA linker. TGA measurements show that after immersing the samples in an $\mathrm{H}_{2} \mathrm{SO}_{4}$ solution, the average number of defects increased from 4.4 to 6.0 defects per cluster (Figure $3 b$ ). Six defects per cluster is considered the maximum of defects to still maintain a stable $3 \mathrm{D}$ UiO-66 framework. ${ }^{3,19}$ As shown in Table 1 and in Figure S11, this observation is accompanied with a reduction in the amount of PSBA and BDC. The relative amount of PSBA that was removed during the acid treatment was higher than the relative amount of BDC linker that was removed upon the treatment (50 and $17 \%$, respectively). Notably, although the number of defects increased after the postsynthetic treatment, the crystalline structure is still preserved (Figure S12). Nevertheless, the Langmuir surface area of Hl-UiO-66 decreased after the treatment in the $\mathrm{H}_{2} \mathrm{SO}_{4}$ solution (Figures 4, S13). HlUiO-66- $\mathrm{SO}_{4}$ has six missing linkers per cluster, which corresponds to a sixfold structure with more defects than the eightfold reo $\mathrm{UiO}-66$. The reo $\mathrm{UiO}-66$ is a structure that possesses ordered missing clusters. ${ }^{43}$

When looking again at the Ar-isotherms (Figure 4), we see that for the $\mathrm{Hl}-\mathrm{UiO}-66-\mathrm{SO}_{4}$, a large interparticle porosity has emerged, indicating that at least some of the particles have reduced into fines. This is corroborated by scanning electron microscopy measurements and a statistical analysis of the size of the particles (Figure S7). From the pore size distributions, it is clear that all micropores reduce significantly; also, the surface area and the pore volume reduce strongly to $928 \mathrm{~m}^{2} \mathrm{~g}^{-1}$ and $213 \mathrm{~cm}^{3} \mathrm{~g}^{-1}$.

The deconvoluted $S$ 2p XPS spectra were analyzed to confirm the presence of sulfonate and sulfate species in $\mathrm{Hl}$ UiO-66-SO ${ }_{4}$ (Figure 2). Two peaks at 168.9 and $170.2 \mathrm{eV}$ (purple hash) in $\mathrm{Hl}-\mathrm{UiO}-66-\mathrm{SO}_{4}$ are attributed to the "freely dangling" phen- $\mathrm{SO}_{3} \mathrm{H}$ of the PSBA linker, whereas the peaks at $169.9 \mathrm{eV}$ and 171.0 (blue plus) in the $\mathrm{UiO}-66-\mathrm{SO}_{4}$ are indicative for these sulfonate groups, coordinated to $\mathrm{Zr}$-sites. This indicates that the PSBA decoordinates after $\mathrm{H}_{2} \mathrm{SO}_{4}$ treatment. Analysis of the deconvoluted bands gives a rough indication of the distribution of the surface species. For the Hl$\mathrm{UiO}-66-\mathrm{SO}_{4}$, approximately $40 \%$ of the sulfur is present as sulfate (blue plus), and $60 \%$ is present as hemilabile linker (purple hash). Further corroboration is found in the oxygen region of the XPS spectra (Figure S19). The O 1s region has a new peak at $534.4 \mathrm{eV}$ in $\mathrm{Hl}-\mathrm{UiO}-66$ compared with UiO-66. This peak is attributed to $\mathrm{Zr}-\mathrm{O}\left(\mathrm{SO}_{3}\right)$. After washing with $\mathrm{H}_{2} \mathrm{SO}_{4}$, this peak mainly disappears, and another peak is found at $532.7 \mathrm{eV}$, attributed to $\mathrm{O} 1 \mathrm{~s}$ of $\mathrm{SO}_{4}{ }^{2-}$.

We made a surprising observation when we performed thermal stability tests of the three MOF materials. TGA experiments show that the thermal stability further increases from $\mathrm{UiO}-66, \mathrm{Hl}-\mathrm{UiO}-66$, to $\mathrm{Hl}-\mathrm{UiO}-66-\mathrm{SO}_{4}$ (Figure 3b). To confirm the result, the variable-temperature powder X-ray diffraction (VTXRD) was performed. As can be seen from Figure S21, these VTXRD results correspond very well to the results obtained from the TGA measurements. A higher thermal stability was observed with increasing numbers of defects which resulted in the following order: UiO-66 (450 $\left.{ }^{\circ} \mathrm{C}\right)<\mathrm{Hl}-\mathrm{UiO}-66\left(480{ }^{\circ} \mathrm{C}\right)<\mathrm{Hl}-\mathrm{UiO}-66-\mathrm{SO}_{4}\left(515{ }^{\circ} \mathrm{C}\right)$. Compared with $\mathrm{Hl}-\mathrm{UiO}-66$ and $\mathrm{UiO}-66$, the sulfonate group of hemilabile ligands makes the $\mathrm{Hl}-\mathrm{UiO}-66-\mathrm{SO}_{4}$ more stable in spite of the high amount of defects. The results correspond to the work of Muesmann et al. concluding that $\mathrm{Cu}$ (BDS) (BDS $=p$-benzenedisulfonate) showed stability higher than that of $\mathrm{Cu}(\mathrm{BDC}){ }^{44}$ The enhanced stability of $\mathrm{Hl}-\mathrm{UiO}-66-\mathrm{SO}_{4}$ suggests that the sulfate groups play an important role in the stabilization of this defective structure. This phenomenon was also observed in pristine UiO-66 (Figure S17).

To obtain a better insight into the structural stability of the modified material, periodic DFT calculations were carried out on the UiO-66 and Hl-UiO-66 materials. For UiO-66, the calculations were performed on the two bricks structure with isolated missing linker defects denoted as type 6 in the work of 


\section{Synthesis of hemilabile UiO-66}
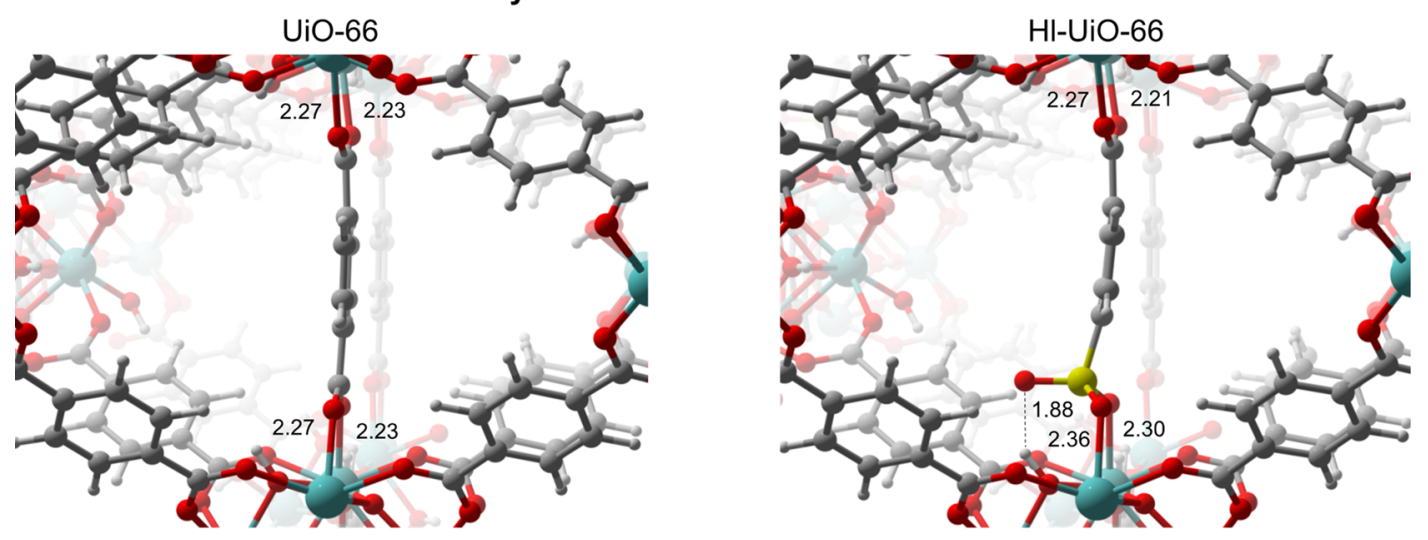

Post-synthetic modification of hemilabile UiO-66 with $\mathrm{H}_{2} \mathrm{SO}_{4}$
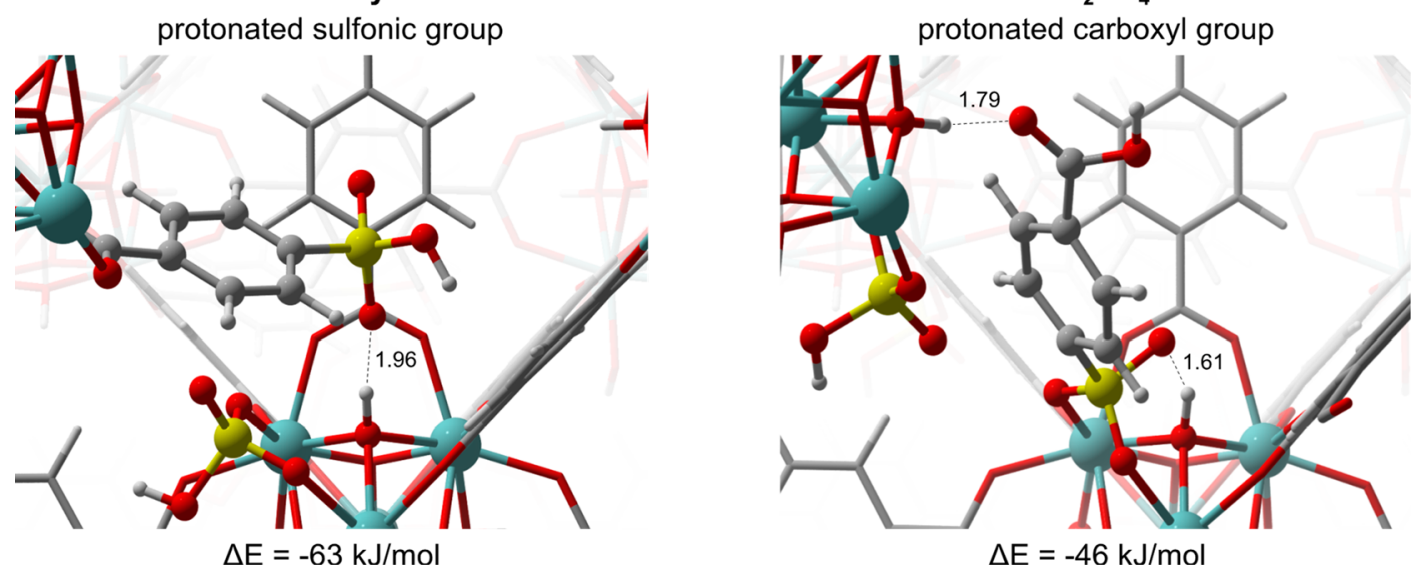

Figure 5. Top: Representation of UiO-66 with one missing linker defect and Hl-UiO-66 with one missing linker defect and one PSBA linker. Bottom: Creation of defects in $\mathrm{Hl}-\mathrm{UiO}-66$ upon postsynthetic treatment with $\mathrm{H}_{2} \mathrm{SO}_{4}$. Representation of geometrically optimized $\mathrm{Hl}-\mathrm{UiO}_{\mathrm{O}}-66-\mathrm{SO}{ }_{4}$ structures in which the PSBA linker is in the dangling state due to protonation of (a) sulfonic and (b) carboxyl group while the $\mathrm{HSO}_{4}^{-}$is adsorbed on the defective site.

Rogge et al. $^{45}$ Each defect site was capped with one chemisorbed water molecule as was indicated by IR studies (Figure S20). The Hl-UiO-66 was constructed accordingly by substituting one out of ten BDC linkers in the defective cluster with a PSBA linker (Figure 5, top). The stability of the materials was calculated based on the difference in electronic energy, following the equation: $\Delta E=\left(E_{\mathrm{HI}-\mathrm{UiO}-66}+E_{\mathrm{BDC}}\right)-$ $\left(E_{\mathrm{UiO}-66}+E_{\mathrm{PSBA}}\right)$. The difference in electronic energy between the Hl-UiO-66 with one PSBA linker and the pristine UiO-66 indicates that the modified material is around $27 \mathrm{~kJ} / \mathrm{mol}$ more stable than UiO-66. Even though the bond between the sulfonate group and $\mathrm{Zr}$ atoms is expected to be weaker, the sulfonate group is stabilized by additional hydrogen bonding interaction with the $\mu_{3}-\mathrm{OH}$ group and one of the three oxygen atoms from the linker (Figure 5, top). The $\mathrm{H}-\mathrm{O}$ distance has "moderate strength", according to the classification of the hydrogen bond of Steiner et al., as it is situated in the range of 1.5-2.2 $\AA^{46,47}$ This additional interaction slightly alters the position of the modified linker. The PSBA linker is bent and therefore the interaction of sulfonate group with $\mathrm{Zr}$ is weaker which is also seen by the longer $\mathrm{Zr}-\mathrm{O}$ bond distance compared to the BDC linker. In the case of a straight configuration, the oxygen atom would be too close to the hydrogen atom causing repulsion. It is due to the bending of the linker that an optimal hydrogen bond distance can be obtained.
To further understand the hemilabile nature of the Hl-UiO66 material, the stability of the PSBA linker protonated by $\mathrm{H}_{2} \mathrm{SO}_{4}$ was investigated. In the acidic solution the PSBA linker can be attacked and protonated either on the sulfonate or carboxyl group which results in the creation of defective site with two adjacent $\mathrm{Zr}$ atoms. Experimental observations indicate that during the postsynthetic treatment with $\mathrm{H}_{2} \mathrm{SO}_{4}$ defects creation occurs on the sulfonate acid group side due to its weaker coordination to the $\mathrm{Zr}$ metal center. Once the linker is protonated by the acid it is in the dangling, metastable state and the $\mathrm{HSO}_{4}^{-}$anion adsorbs on the coordinatively unsaturated $\mathrm{Zr}$ centers (Figure 5, bottom). The dangling linker is always stabilized by hydrogen bond interaction of moderate strength with the neighboring $\mu_{3}-\mathrm{OH}$ group. The stability of the material with dangling, protonated PSBA linker was calculated by the following expression: $\Delta E=$ $\left(E_{\mathrm{Hl}-\mathrm{UiO}-66-\mathrm{H}_{2} \mathrm{SO}_{4}}\right)-\left(E_{\mathrm{Hl}-\mathrm{UiO}-66}+E_{\mathrm{H}_{2} \mathrm{SO}_{4}}\right)$, in which $E_{\mathrm{Hl}-\mathrm{UiO}-66-\mathrm{H}_{2} \mathrm{SO}_{4}}$ stands for either protonated carboxyl or sulfonate group of PSBA. The electronic structure calculations show that the protonated sulfonate group with adsorbed $\mathrm{HSO}_{4}^{-}$anion is around $17 \mathrm{~kJ} / \mathrm{mol}$ more stable than the protonated carboxyl group. This indicates that upon postsynthetic treatment the defects creation is initiated by the cleavage of $\mathrm{Zr}$-sulfonic acid group bond. The sulfonate group is a weaker base than the carboxyl group and therefore it is the best leaving group. These calculations confirmed that the 
creation of defects in $\mathrm{Hl}-\mathrm{UiO}-66$ occurs preferentially by removal of PSBA linkers. Second, to gain computational insight in the origin of the increased stability of Hl-UiO-66 after treatment, we calculated the free energies of defective and nondefective structures of $\mathrm{Hl}-\mathrm{UiO}-66$ within the harmonic approximation. In contrast to the electronic energy, the free energy includes contributions due to the normal modes such as vibrational entropy. In this way, temperature effects could be estimated. We have found that, at $300 \mathrm{~K}$, defective structures have an entropy that is about $100 \mathrm{~J} / \mathrm{mol} / \mathrm{K}$ higher than nondefective structures. Even when considering the approximation of our approach, this large entropy difference is a clear indication that defective structures are entropically favored above nondefective structures at high temperatures.

Lewis and Brønsted Sites, Catalytic Activity. The defects in UiO-66 have been widely studied but their role of acidity is not yet always clear. ${ }^{2,48} \mathrm{De}$ Vos and coworkers reported an approach using trifluoroacetic acid as a modulator to create defects as Lewis acid sites. The Lewis acid catalyzed Meerwein-Ponndorf-Verley reaction of 4-tert-butylcyclohexanone $(\mathrm{TCH})$ and isopropanol was used as a probe reaction, and the nature and amount of the acid sites was measured by IR-monitored $\mathrm{CD}_{3} \mathrm{CN}$ chemisorption. ${ }^{14}$ Hereafter, the defects as Lewis acid sites have been explored frequently. ${ }^{2}$ The defects as Brønsted acid sites were evaluated by potentiometric acidbase titration and then correlated with the Brønsted acid catalyzed epoxide ring-opening reaction with alcohol. ${ }^{49,50}$ Recent discoveries about UiO-66 have shown that after defect engineering the material possesses not only Lewis acid sites but also a significant number of Brønsted sites which induce a very dynamic acidity. ${ }^{51-53}$ This property of the Brønsted sites in UiO-66 plays a crucial role in the reactions where proton rearrangement can occur. ${ }^{54-56}$ It is critical to identify the roles of these defects in catalysis, either Lewis sites or Brønsted sites or Lewis sites and Brønsted sites together. Several studies characterized the defects using Fourier transform infrared (FTIR) or FT-IR with CO or titration. ${ }^{14,49,57,58}$ Herein, the isomerization of $\alpha$-pinene oxide as probe reaction was examined to identify and verify the roles of defect under in situ catalytic condition.

$\alpha$-Pinene oxide is a very sensitive substrate which rearranges easily under the influence of a Lewis or Brønsted acid based catalyst. One of the formed products during the Lewis-acidcatalyzed rearrangement of $\alpha$-pinene oxide is campholenic aldehyde (CA), an intermediate in the production of sandalwood fragrance and santalol. ${ }^{59,60}$ The other major products produced during this acid-catalyzed isomerization are summarized in Scheme 1. The selectivity during the isomerization of $\alpha$-pinene depends highly on the type of acid sites present in the reaction medium. This makes the reaction a powerful probe to determine the types of acid sites present in the catalysts. ${ }^{61}$ Brønsted acids behave differently than Lewis acids for the formation of CA. More specifically, a high selectivity toward CA (up to $85 \%$ ) was obtained using catalysts with only Lewis acid sites, whereas for the Brønsted acid catalyzed reaction this selectivity is lower than $55 \%$ and a significant amount of trans-carveol is formed. ${ }^{61}$

The catalytic activity of $\mathrm{HI}-\mathrm{UiO}-66$ was examined for the isomerization of $\alpha$-pinene oxide in toluene at a reaction temperature of $70^{\circ} \mathrm{C}$. Prior to the catalytic tests, the materials were activated under vacuum at $150{ }^{\circ} \mathrm{C}$ for $16 \mathrm{~h}$. As can be seen from Figure 6, the pristine UiO-66 exhibited a conversion of $\alpha$-pinene oxide of $54 \%$ after a reaction time of $3 \mathrm{~h}$, whereas
Scheme 1. Formation of Different Products during the Isomerization of $\alpha$-Pinene Oxide
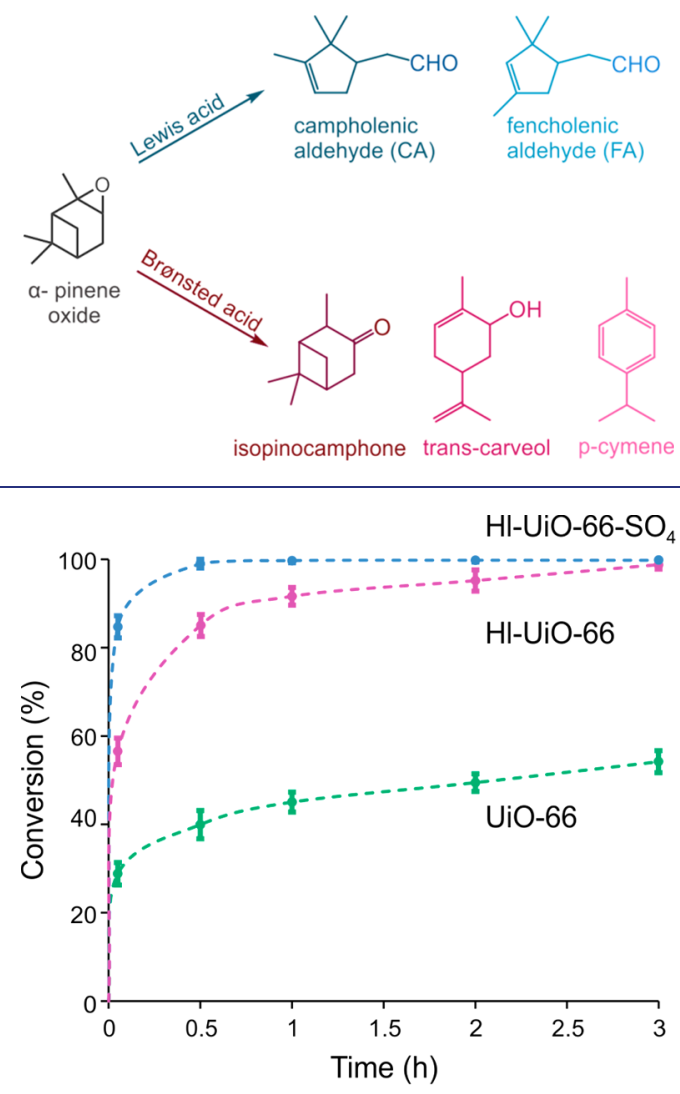

Figure 6. Conversion vs time for the isomerization of $\alpha$-pinene oxide over $\mathrm{UiO}-66$ and $\mathrm{Hl}-\mathrm{UiO}-66$ and $\mathrm{Hl}-\mathrm{UiO}-66-\mathrm{SO}_{4}$.

for $\mathrm{Hl}-\mathrm{UiO}-66$, full conversion was obtained under the same reaction conditions. Remarkably, for Hl-UiO-66 and Hl-UiO$66-\mathrm{SO}_{4}, 85$ and $99 \%$ conversion was achieved respectively within only $30 \mathrm{~min}$ of reaction time (Figure 6). Therefore, the catalytic activity follows the order: $\mathrm{Hl}-\mathrm{UiO}-66-\mathrm{SO}_{4}>\mathrm{Hl}-\mathrm{UiO}-$ $66>\mathrm{UiO}-66$, corroborating that the number of defects influences the rate of the isomerization reactions.

As can be seen from Figure 7, the Hl-UiO-66 and Hl-UiO$66-\mathrm{SO}_{4}$ exhibit a higher selectivity $(>55 \%)$ to $\mathrm{CA}$ than the pristine UiO-66 material (47\%). The observed reactivity of $\mathrm{Hl}-$ UiO-66 and $\mathrm{Hl}-\mathrm{UiO}-66-\mathrm{SO}_{4}$ are comparable to that of other Lewis acid based catalysts (such as Cu-BTC) while the reactivity of $\mathrm{UiO}-66$ is comparable to that of Brønsted acid catalysts such as Dowex 50Wx4-100. ${ }^{59}$ To understand the selectivity in these three $\mathrm{Zr}-\mathrm{MOF}$, it is necessary to know the nature of the active sites, whether they reveal Lewis or Brønsted acidity.

The acid character of all three MOFs was assessed by the adsorption of acetonitrile- $\mathrm{d}_{3}\left(\mathrm{CD}_{3} \mathrm{CN}\right)$ followed by FT-IR. Figure 8 (left) shows the difference in IR spectra of adsorbed $\mathrm{CD}_{3} \mathrm{CN}$ on the evacuated MOFs (normalized to $10 \mathrm{mg} / \mathrm{cm}^{2}$ ), in which three $\nu(\mathrm{CN})$ vibrational bands can be observed at 2299, 2272, and $2260 \mathrm{~cm}^{-1}$. These bands can be attributed to the adsorption of $\mathrm{CD}_{3} \mathrm{CN}$ on Lewis and Brønsted acid sites and to physisorbed $\mathrm{CD}_{3} \mathrm{CN}$, respectively. ${ }^{14,62}$ Lewis acid sites in UiO-66 are associated with the dehydroxylation process of the inorganic cluster and are present in all the studied MOFs. However, small differences in the position of the band and in its intensity are observed in the spectra. These bands appear on 


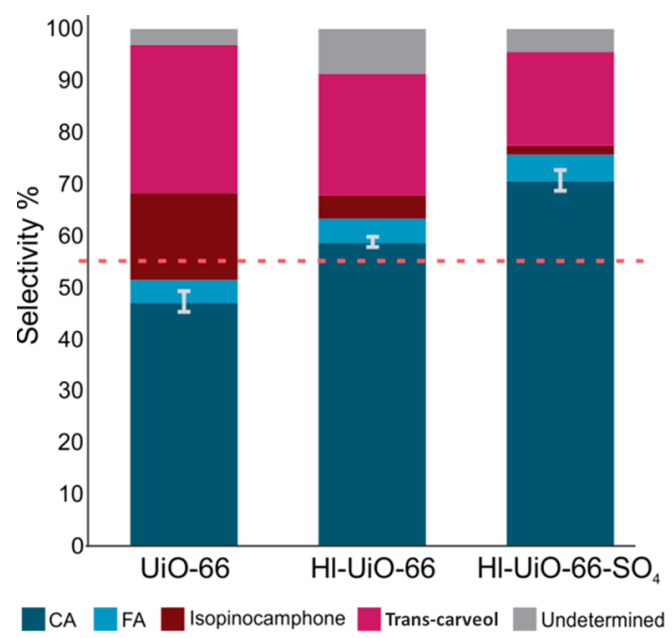

Figure 7. Product selectivity for the isomerization of $\alpha$-pinene oxide at $100 \%$ conversion over $\mathrm{UiO}-66$ and $\mathrm{Hl}-\mathrm{UiO}-66$ and $\mathrm{Hl}-\mathrm{UiO}-66$ washed with $\mathrm{H}_{2} \mathrm{SO}_{4}$ solution. The dotted line indicates the selectivity of $55 \%$.

the modified UiO-66 samples at a slightly higher wavenumber $\left(2299 \mathrm{~cm}^{-1}\right)$ than on the spectrum of the pristine UiO-66 $\left(2296 \mathrm{~cm}^{-1}\right)$, which suggests a higher Lewis acid strength. ${ }^{63}$ Furthermore, the intensity of such band decreases in the order $\mathrm{Hl}-\mathrm{UiO}-66-\mathrm{SO}_{4}>\mathrm{Hl}-\mathrm{UiO}-66>\mathrm{UiO}-66$.

In Figure 8 (right), the normalized band area of all the studied MOFs shows this clear trend, which is a direct indication of the enhancement in the number of defects that can be created by the use of hemilabile ligands and further treatment with $\mathrm{H}_{2} \mathrm{SO}_{4}$. These results are in agreement with the catalytic activity test and the higher selectivity to CA exhibited by the samples $\mathrm{Hl}-\mathrm{UiO}-66-\mathrm{SO}_{4}$ and $\mathrm{Hl}-\mathrm{UiO}-66$. An opposite trend is obtained when the band at $2272 \mathrm{~cm}^{-1}$ is analyzed. This band is related to the amount of Brønsted acid sites in the structure that can originate from the $\mu_{3}-\mathrm{OH}$ groups of the inorganic cluster. ${ }^{63}$ Whereas this band is only present as a shoulder on the spectra of the samples $\mathrm{Hl}-\mathrm{UiO}-66-\mathrm{SO}_{4}$ and $\mathrm{Hl}-$ $\mathrm{UiO}-66$, it is quite prominent in the spectrum of the pure $\mathrm{UiO}$ 66 , which indicates a higher relative amount of Brønsted acid sites on the latter. Such trend is also easily visualized in Figure 8 (right) and the results also correlate with the catalytic activity tests where UiO-66 behaved more like a Brønsted acid, forming CA with a selectivity of only $47 \%$.

A perfect UiO-66 contains four Brønsted acidic sites $\left(\mu_{3}-\right.$ $\mathrm{OH})$ per cluster and no Lewis acidic sites. Yang et al. showed that one defect site in UiO-66 results in one Lewis $(\mathrm{Zr}$ vacancy) and one Brønsted $(\mathrm{Zr}-\mathrm{OH})$ acid site (Figure S20, Scheme 1). ${ }^{57,64,65}$ But, upon thermal treatment, the two Brønsted sites $\left(\mathrm{Zr}-\mathrm{OH}\right.$ and $\left.\mu_{3}-\mathrm{OH}\right)$ in this defective $\mathrm{UiO}-66$ will dehydroxylate annihilating both Brønsted sites and forming a $\mathrm{Zr}-\mathrm{O}-\mathrm{Zr}$ linkage. As a result, a dehydroxylated UiO-66 with $x$ defects contains $4-x$ Brønsted acid sites and $x$ Lewis acid sites. In our case, the UiO-66 contains 1.7 defects resulting in 2.3 Brønsted acidic sites and 1.7 Lewis acidic sites per cluster with a ratio of Brønsted to Lewis acidic sites of 1.35 (2.3/1.7). Similarly, Hl-UiO-66 contains 1.8 Brønsted acidic sites and 2.2 Lewis acidic sites per cluster with a ratio of 0.82 and $\mathrm{Hl}-\mathrm{UiO}-66-\mathrm{SO}_{4}$ contains 1.0 Brønsted acidic sites and 3.0 Lewis acidic sites per cluster with a ratio of 0.33 . It is clear that upon increasing the number of defects, the amount of Lewis acidic sites increases, resulting in the enhanced selectivity to $\mathrm{CA}$. Since $\mathrm{Hl}-\mathrm{UiO}-66-\mathrm{SO}_{4}$ has the highest number of defects, and the highest ratio of Lewis sites to Brønsted sites, it has the highest selectivity toward CA in comparison to the other two catalysts. These observations are consistent with the results obtained from $\mathrm{CD}_{3} \mathrm{CN}$ adsorption analysis. The Brønsted acid sites are dominant in UiO-66 with a low defect density while the Lewis acid sites are prominent in $\mathrm{Hl}-\mathrm{UiO}-66-\mathrm{SO}_{4}$ with a high defect density.

To compare the reactivity of these $\mathrm{Zr}$-MOF materials with the other heterogeneous MOF based catalysts and zeolites, we summarize the reactivity and selectivity of some published catalysts in Table S3. From this table, Hl-UiO-66-SO $\mathrm{SO}_{4}$ shows the best activity and selectivity in comparison to the other reported MOF catalysts. In comparison to $\mathrm{Cu}_{3}(\mathrm{BTC})_{2}, 59,66$ which only has Lewis acid sites, a higher catalytic activity but a lower selectivity was obtained. However, this catalyst is not stable and cannot be recycled. Compared to the best homogeneous Lewis-acid catalyst $\left(\mathrm{ZnBr}_{2}\right),{ }^{67}$ the Hl-UiO-66$\mathrm{SO}_{4}$ exhibits a similar selectivity but with a higher turnover.

In addition, a hot filtration test after $3 \mathrm{~min}$ of reaction revealed that after the removal of the catalyst no further conversion was noted, confirming the heterogeneous nature of the catalyst (Figure S23). Nevertheless, during the recycling experiments, the activity and selectivity decreased slightly
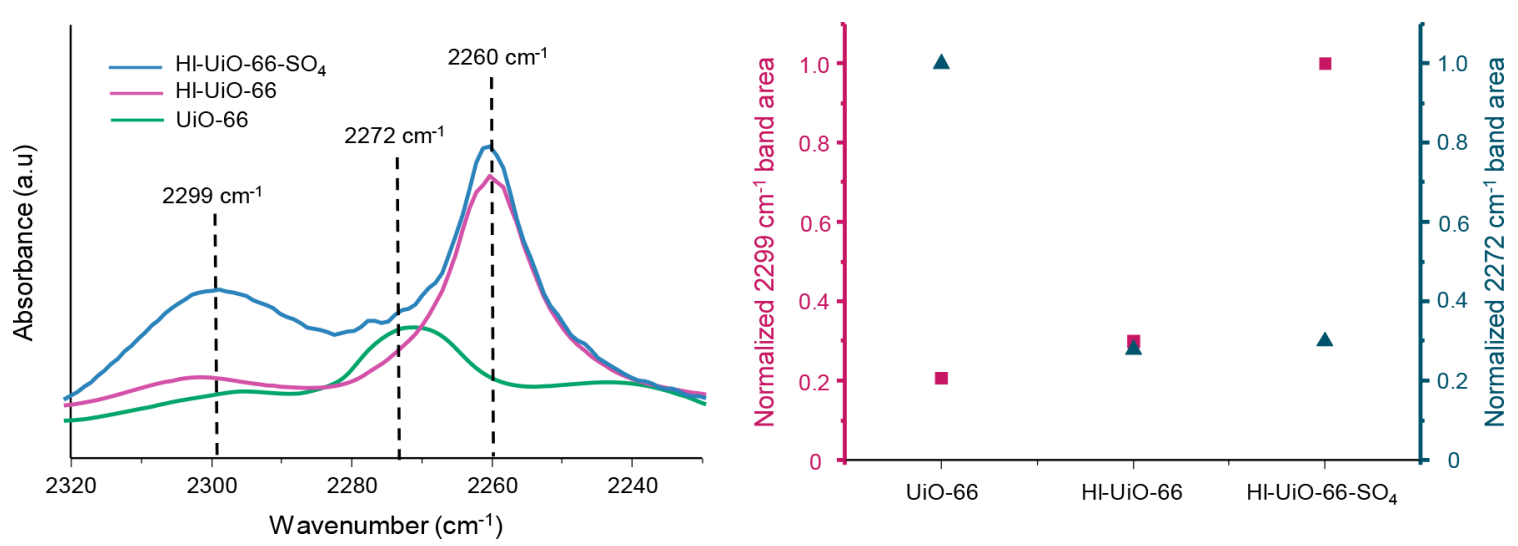

Figure 8. Left: Difference IR spectra of adsorbed $\mathrm{CD}_{3} \mathrm{CN}$ (normalized to $10 \mathrm{mg} / \mathrm{cm}^{2}$ ). $\mathrm{CD}_{3} \mathrm{CN}$ was adsorbed at room temperature for $1 \mathrm{~h}$ and desorbed under vacuum for $1 \mathrm{~h}$. Right: Amount of Brønsted (triangles) and Lewis (squares) acid sites detected by $\mathrm{CD}_{3} \mathrm{CN}$, expressed as normalized area of the bands at 2272 and $2299 \mathrm{~cm}^{-1}$, respectively. 
during each run (Figure S24). This decrease might be due to the blocking of the pores during the consecutive runs, as the surface area slightly decreased during each run (Figure S26). PXRD measurements showed that the structure remained intact (Figure S25).

\section{CONCLUSIONS}

In summary, we presented a stable yet highly defective $\mathrm{Zr}$ MOF, obtained using the hemilabile linker strategy. PSBA not only acts as a modulator for the MOF synthesis to increase the number of defects but also as coligand to stabilize the defective structure. The Hl-UiO-66 is one of the first reported frameworks that further stabilizes (instead of the typical destabilization) as the number of defects increases. A simple postsynthetic treatment with $\mathrm{H}_{2} \mathrm{SO}_{4}$ even further enhances the stability while the number of defects sites increases again. This $\mathrm{Hl}-\mathrm{UiO}-66-\mathrm{SO}_{4}$ showed the optimum number of defects (while maintaining structural integrity) and showed the highest reactivity for the acid-catalyzed isomerization of $\alpha$-pinene oxide with a high selectivity for campholenic aldehyde. We also found that the increase in the number of defects increases the Lewis acid characteristics and hence favors the campholenic aldehyde formation. By controlling the number of defects, we can tune the acid behavior of the catalysts, as a low number of defects leads to a Bronsted dominated catalyst, and vice versa. The nature and concentration of the defective sites were further elucidated by IR-monitored $\mathrm{CD}_{3} \mathrm{CN}$ sorption. The use of a hemilabile linker, either as mixed linker or as the isolated linker, is an interesting concept in defect engineering of MOFs. Due to the different possibilities in coordination ability of the two different groups in a hemilabile linker, defects can be generated and hence the stability can be affected. Meanwhile, the easy postsynthetic treatment can be useful to adapt and adjust the final structure of the pristine materials for potential applications.

\section{ASSOCIATED CONTENT}

\section{SI Supporting Information}

The Supporting Information is available free of charge at https://pubs.acs.org/doi/10.1021/jacs.9b13070.

Detailed catalysis results and data analysis results including PXRD, VTXRD, TGA-DSC, dissolution $/{ }^{1} \mathrm{H}$ NMR, nitrogen adsorption IR, catalysis results, and the modeling data (PDF)

Structures (ZIP)

\section{AUTHOR INFORMATION}

\section{Corresponding Author}

Pascal Van Der Voort - Department of Chemistry, Center for Ordered Materials, Organometallics and Catalysis (COMOC), Ghent University, B-9000 Ghent, Belgium; - orcid.org/00000002-4874-0943; Email: pascal.vandervoort@ugent.be

\section{Authors}

Xiao Feng - Department of Chemistry, Center for Ordered Materials, Organometallics and Catalysis (COMOC), Ghent University, B-9000 Ghent, Belgium

Julianna Hajek - Center for Molecular Modeling, Ghent University, 9052 Zwijnaarde, Belgium

Himanshu Sekhar Jena - Department of Chemistry, Center for Ordered Materials, Organometallics and Catalysis (COMOC),

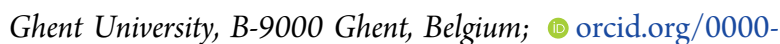
0002-5869-5226

Guangbo Wang - Department of Chemistry, Center for Ordered Materials, Organometallics and Catalysis (COMOC), Ghent University, B-9000 Ghent, Belgium; College of Chemistry, Chemical Engineering and Materials Science, Collaborative Innovation Center of Functionalized Probes for Chemical Imaging in Universities of Shandong, Key Laboratory of Molecular and Nano Probes, Ministry of Education, Shandong Normal University, Jinan 250014, P.R. China

Savita K.P. Veerapandian - Research Unit Plasma Technology (RUPT), Department of Applied Physics, Faculty of Engineering and Architecture, Ghent University, 9000 Ghent, Belgium; (1) orcid.org/0000-0003-4652-8487

Rino Morent - Research Unit Plasma Technology (RUPT), Department of Applied Physics, Faculty of Engineering and Architecture, Ghent University, 9000 Ghent, Belgium

Nathalie De Geyter - Research Unit Plasma Technology (RUPT), Department of Applied Physics, Faculty of Engineering and Architecture, Ghent University, 9000 Ghent, Belgium

Karen Leyssens - Department of Chemistry, Lab of Adsorption \& Catalysis LADCA, University of Antwerp, B-2610 Antwerp, Belgium

Alexander E.J. Hoffman - Center for Molecular Modeling, Ghent University, 9052 Zwijnaarde, Belgium; 이이. orcid 0000-0002-1529-4705

Vera Meynen - Department of Chemistry, Lab of Adsorption \& Catalysis LADCA, University of Antwerp, B-2610 Antwerp, Belgium; (1) orcid.org/0000-0002-9867-6986

Carlos Marquez - Ctr Membrane Separation, Adsorption, Catalysis \& Spectroscopy for Sustainable Chemistry, Katholieke University Leuven, B-3000 Leuven, Belgium; 이이.org/ 0000-0001-7382-683X

Dirk E. De Vos - Ctr Membrane Separation, Adsorption, Catalysis \& Spectroscopy for Sustainable Chemistry, Katholieke University Leuven, B-3000 Leuven, Belgium

Veronique Van Speybroeck - Center for Molecular Modeling, Ghent University, 9052 Zwijnaarde, Belgium; 이이.org/ 0000-0003-2206-178X

Karen Leus - Department of Chemistry, Center for Ordered Materials, Organometallics and Catalysis (COMOC), Ghent University, B-9000 Ghent, Belgium

Complete contact information is available at:

https://pubs.acs.org/10.1021/jacs.9b13070

\section{Notes}

The authors declare no competing financial interest.

\section{ACKNOWLEDGMENTS}

X.F. and G.W. gratefully acknowledge the Chinese Scholarship Council (CSC) and Ghent University BOF Co-funding grant for financial support. K.L. acknowledges the financial support from Ghent University. H.S.J. thanks FWO[PEGASUS $]^{2}$ Marie Sklodowska-Curie Grant 665501. Davy Deduytsche and Kristof Detavernier are kindly acknowledged for VTXRD. V.V.S., A.E.J.H., and J.H. further acknowledge financial support from the European Research Council (Grant Agreement Agency (research core funding no. 647755, acronym: DYNPOR) and the Research Board of Ghent University (BOF). The computational resources and services used in this work were provided by the VSC (Flemish Supercomputer 
Center), funded by the FWO. The authors acknowledge Katrien Haustraete for TEM analysis and mapping.

\section{REFERENCES}

(1) Bai, Y.; Dou, Y.; Xie, L. H.; Rutledge, W.; Li, J. R.; Zhou, H. C. Zr-based metal-organic frameworks: design, synthesis, structure, and applications. Chem. Soc. Rev. 2016, 45 (8), 2327-2367.

(2) Fang, Z.; Bueken, B.; De Vos, D. E.; Fischer, R. A. DefectEngineered Metal-Organic Frameworks. Angew. Chem., Int. Ed. 2015, 54 (25), 7234-7254.

(3) Shearer, G. C.; Chavan, S.; Bordiga, S.; Svelle, S.; Olsbye, U.; Lillerud, K. P. Defect Engineering: Tuning the Porosity and Composition of the Metal-Organic Framework UiO-66 via Modulated Synthesis. Chem. Mater. 2016, 28 (11), 3749-3761.

(4) Cavka, J. H.; Jakobsen, S.; Olsbye, U.; Guillou, N.; Lamberti, C.; Bordiga, S.; Lillerud, K. P. A new zirconium inorganic building brick forming metal organic frameworks with exceptional stability. J. Am. Chem. Soc. 2008, 130 (42), 13850-13851.

(5) Trickett, C. A.; Gagnon, K. J.; Lee, S.; Gandara, F.; Buergi, H.-B.; Yaghi, O. M. Definitive Molecular Level Characterization of Defects in UiO-66 Crystals. Angew. Chem., Int. Ed. 2015, 54 (38), 1116211167.

(6) Jena, H. S.; Kaczmarek, A. M.; Krishnaraj, C.; Feng, X.; Vijayvergia, K.; Yildirim, H.; Zhao, S.-N.; Van Deun, R.; Der Voort, P. V. White Light Emission Properties of Defect Engineered MetalOrganic Frameworks by Encapsulation of Eu3+ and Tb3+. Cryst. Growth Des. 2019, 19 (11), 6339-6350.

(7) Vermoortele, F.; Bueken, B.; Le Bars, G. 1.; Van de Voorde, B.; Vandichel, M.; Houthoofd, K.; Vimont, A.; Daturi, M.; Waroquier, M.; Van Speybroeck, V. Synthesis Modulation as a Tool To Increase the Catalytic Activity of Metal-Organic Frameworks: The Unique Case of UiO-66 (Zr). J. Am. Chem. Soc. 2013, 135 (31), 1146511468.

(8) Vandichel, M.; Hajek, J.; Vermoortele, F.; Waroquier, M.; De Vos, D. E.; Van Speybroeck, V. Active site engineering in UiO-66 type metal-organic frameworks by intentional creation of defects: a theoretical rationalization. CrystEngComm 2015, 17 (2), 395-406.

(9) Morris, W.; Wang, S.; Cho, D.; Auyeung, E.; Li, P.; Farha, O. K.; Mirkin, C. A. Role of Modulators in Controlling the Colloidal Stability and Polydispersity of the UiO-66 Metal-Organic Framework. ACS Appl. Mater. Interfaces 2017, 9 (39), 33413-33418.

(10) Hao, L.; Li, X.; Hurlock, M. J.; Tu, X.; Zhang, Q. Hierarchically porous UiO-66: facile synthesis, characterization and application. Chem. Commun. 2018, 54 (83), 11817-11820.

(11) Feng, L.; Yuan, S.; Zhang, L.-L.; Tan, K.; Li, J.-L.; Kirchon, A.; Liu, L.-M.; Zhang, P.; Han, Y.; Chabal, Y. J.; Zhou, H.-C. Creating Hierarchical Pores by Controlled Linker Thermolysis in Multivariate Metal-Organic Frameworks. J. Am. Chem. Soc. 2018, 140 (6), 23632372.

(12) Cai, G.; Jiang, H.-L. A Modulator-Induced Defect-Formation Strategy to Hierarchically Porous Metal-Organic Frameworks with High Stability. Angew. Chem., Int. Ed. 2017, 56 (2), 563-567.

(13) Yang, P.; Mao, F.; Li, Y.; Zhuang, Q.; Gu, J. Hierarchical Porous Zr-Based MOFs Synthesized by a Facile Monocarboxylic Acid Etching Strategy. Chem. - Eur. J. 2018, 24 (12), 2962-2970.

(14) Vermoortele, F.; Bueken, B.; Le Bars, G.; Van de Voorde, B.; Vandichel, M.; Houthoofd, K.; Vimont, A.; Daturi, M.; Waroquier, M.; Van Speybroeck, V.; Kirschhock, C.; De Vos, D. E. Synthesis Modulation as a Tool To Increase the Catalytic Activity of MetalOrganic Frameworks: The Unique Case of UiO-66(Zr). J. Am. Chem. Soc. 2013, 135 (31), 11465-11468.

(15) Feng, X.; Jena, H. S.; Leus, K.; Wang, G.; Ouwehand, J.; Van Der Voort, P. 1 -proline modulated zirconium metal organic frameworks: Simple chiral catalysts for the aldol addition reaction. J. Catal. 2018, 365, 36-42.

(16) Rogge, S. M. J.; Bavykina, A.; Hajek, J.; Garcia, H.; OlivosSuarez, A. I.; Sepulveda-Escribano, A.; Vimont, A.; Clet, G.; Bazin, P.; Kapteijn, F.; Daturi, M.; Ramos-Fernandez, E. V.; Llabres i Xamena, F. X.; Van Speybroeck, V.; Gascon, J. Metal-organic and covalent organic frameworks as single-site catalysts. Chem. Soc. Rev. 2017, 46 (11), 3134-3184.

(17) Shearer, G. C.; Chavan, S.; Ethiraj, J.; Vitillo, J. G.; Svelle, S.; Olsbye, U.; Lamberti, C.; Bordiga, S.; Lillerud, K. P. Tuned to Perfection: Ironing Out the Defects in Metal-Organic Framework UiO-66. Chem. Mater. 2014, 26 (14), 4068-4071.

(18) Atzori, C.; Shearer, G. C.; Maschio, L.; Civalleri, B.; Bonino, F.; Lamberti, C.; Svelle, S.; Lillerud, K. P.; Bordiga, S. Effect of Benzoic Acid as a Modulator in the Structure of UiO-66: An Experimental and Computational Study. J. Phys. Chem. C 2017, 121 (17), 9312-9324.

(19) Bueken, B.; Van Velthoven, N.; Krajnc, A.; Smolders, S.; Taulelle, F.; Mellot-Draznieks, C.; Mali, G.; Bennett, T. D.; De Vos, D. Tackling the Defect Conundrum in UiO-66: A Mixed-Linker Approach to Engineering Missing Linker Defects. Chem. Mater. 2017, 29 (24), 10478-10486.

(20) Morris, R. E.; Brammer, L. Coordination change, lability and hemilability in metal-organic frameworks. Chem. Soc. Rev. 2017, 46 (17), 5444-5462.

(21) Xiao, B.; Byrne, P. J.; Wheatley, P. S.; Wragg, D. S.; Zhao, X.; Fletcher, A. J.; Thomas, K. M.; Peters, L.; Evans, J. S. O.; Warren, J. E.; Zhou, W.; Morris, R. E. Chemically blockable transformation and ultraselective low-pressure gas adsorption in a non-porous metal organic framework. Nat. Chem. 2009, 1 (4), 289-294.

(22) McHugh, L. N.; McPherson, M. J.; McCormick, L. J.; Morris, S. A.; Wheatley, P. S.; Teat, S. J.; McKay, D.; Dawson, D. M.; Sansome, C. E. F.; Ashbrook, S. E.; Stone, C. A.; Smith, M. W.; Morris, R. E. Hydrolytic stability in hemilabile metal-organic frameworks. Nat. Chem. 2018, 10 (11), 1096-1102.

(23) Shimizu, G. K. H.; Vaidhyanathan, R.; Taylor, J. M. Phosphonate and sulfonate metal organic frameworks. Chem. Soc. Rev. 2009, 38 (5), 1430-1449.

(24) Serre, C.; Millange, F.; Thouvenot, C.; Noguès, M.; Marsolier, G.; Louër, D.; Férey, G. Very Large Breathing Effect in the First Nanoporous Chromium(III)-Based Solids: MIL-53 or $\mathrm{CrIII}(\mathrm{OH})$. $\{\mathrm{O} 2 \mathrm{C}-\mathrm{C} 6 \mathrm{H} 4-\mathrm{CO} 2\} \cdot\{\mathrm{HO} 2 \mathrm{C}-\mathrm{C} 6 \mathrm{H} 4-\mathrm{CO} 2 \mathrm{H}\} \mathrm{x} \cdot \mathrm{H} 2 \mathrm{Oy} . J . A m$. Chem. Soc. 2002, 124 (45), 13519-13526.

(25) Biswas, S.; Van Der Voort, P. A General Strategy for the Synthesis of Functionalised UiO-66 Frameworks: Characterisation, Stability and $\mathrm{CO} 2$ Adsorption Properties. Eur. J. Inorg. Chem. 2013, 2013 (12), 2154-2160.

(26) Kresse, G.; Joubert, D. From ultrasoft pseudopotentials to the projector augmented-wave method. Phys. Rev. B: Condens. Matter Mater. Phys. 1999, 59 (3), 1758-1775.

(27) Kresse, G.; Furthmüller, J. Efficient iterative schemes for $a b$ initio total-energy calculations using a plane-wave basis set. Phys. Rev. B: Condens. Matter Mater. Phys. 1996, 54 (16), 11169-11186.

(28) Kresse, G.; Furthmüller, J. Efficiency of ab-initio total energy calculations for metals and semiconductors using a plane-wave basis set. Comput. Mater. Sci. 1996, 6 (1), 15-50.

(29) Kresse, G.; Hafner, J. Ab initio molecular-dynamics simulation of the liquid-metal-amorphous-semiconductor transition in germanium. Phys. Rev. B: Condens. Matter Mater. Phys. 1994, 49 (20), 14251-14269.

(30) Kresse, G.; Hafner, J. Ab initio molecular dynamics for liquid metals. Phys. Rev. B: Condens. Matter Mater. Phys. 1993, 47 (1), 558561.

(31) Blöchl, P. E. Projector augmented-wave method. Phys. Rev. B: Condens. Matter Mater. Phys. 1994, 50 (24), 17953-17979.

(32) Perdew, J. P.; Burke, K.; Ernzerhof, M. Generalized Gradient Approximation Made Simple. Phys. Rev. Lett. 1996, 77 (18), 38653868.

(33) Grimme, S.; Antony, J.; Ehrlich, S.; Krieg, H. A consistent and accurate $\mathrm{ab}$ initio parametrization of density functional dispersion correction (DFT-D) for the 94 elements H-Pu. J. Chem. Phys. 2010, 132 (15), 154104.

(34) Grimme, S. Accurate description of van der Waals complexes by density functional theory including empirical corrections. J. Comput. Chem. 2004, 25 (12), 1463-1473. 
(35) Vinet, P.; Rose, J. H.; Ferrante, J.; Smith, J. R. Universal features of the equation of state of solids. J. Phys.: Condens. Matter 1989, 1 (11), 1941-1963.

(36) Ghysels, A.; Verstraelen, T.; Hemelsoet, K.; Waroquier, M.; Van Speybroeck, V. TAMkin: A Versatile Package for Vibrational Analysis and Chemical Kinetics. J. Chem. Inf. Model. 2010, 50 (9), $1736-1750$

(37) Liu, Y.; Su, J.; Li, W.; Wu, J. First hydrotalcite-like sulfonate coordination network incorporating robust cationic layers and flexible interlayer interactions. Inorg. Chem. 2005, 44 (11), 3890-3895.

(38) Sun, B.; Zhao, Y.; Wu, J.-G.; Yang, Q.-C.; Xu, G.-X. Crystal structure and FT-IR study of cesium 4-methylbenzenesulfonate. $J$. Mol. Struct. 1998, 471 (1-3), 63-66.

(39) Haynes, J. S.; Sams, J. R.; Thompson, R. C. Synthesis and structural studies of iron (II) and iron (III) sulfonates. Can. J. Chem. 1981, 59 (4), 669-678.

(40) Fleutot, S.; Martinez, H.; Dupin, J.-C.; Baraille, I.; Forano, C.; Renaudin, G.; Gonbeau, D. Experimental (X-Ray Photoelectron Spectroscopy) and theoretical studies of benzene based organics intercalated into layered double hydroxide. Solid State Sci. 2011, 13 (9), 1676-1686.

(41) Valenzano, L.; Civalleri, B.; Chavan, S.; Bordiga, S.; Nilsen, M. H.; Jakobsen, S.; Lillerud, K. P.; Lamberti, C. Disclosing the complex structure of UiO-66 metal organic framework: a synergic combination of experiment and theory. Chem. Mater. 2011, 23 (7), 1700-1718.

(42) Cliffe, M. J.; Wan, W.; Zou, X.; Chater, P. A.; Kleppe, A. K.; Tucker, M. G.; Wilhelm, H.; Funnell, N. P.; Coudert, F.-X.; Goodwin, A. L. Correlated defect nanoregions in a metal-organic framework. Nat. Commun. 2014, 5, 4176.

(43) Cliffe, M. J.; Wan, W.; Zou, X.; Chater, P. A.; Kleppe, A. K.; Tucker, M. G.; Wilhelm, H.; Funnell, N. P.; Coudert, F. X.; Goodwin, A. L. Correlated defect nanoregions in a metal-organic framework. Nat. Commun. 2014, 5, 4176.

(44) Muesmann, T. W.; Zitzer, C.; Mietrach, A.; Kluner, T.; Christoffers, J.; Wickleder, M. S. para-Benzene disulfonic acid and its tetrachloro and tetrafluoro derivatives-studies towards polyhalogenated metal-organic-frameworks with sulfo analogues of terephthalic acid. Dalton Trans 2011, 40 (13), 3128-41.

(45) Rogge, S. M. J.; Wieme, J.; Vanduyfhuys, L.; Vandenbrande, S.; Maurin, G.; Verstraelen, T.; Waroquier, M.; Van Speybroeck, V. Thermodynamic Insight in the High-Pressure Behavior of UiO-66: Effect of Linker Defects and Linker Expansion. Chem. Mater. 2016, 28 (16), 5721-5732.

(46) Steiner, T. The hydrogen bond in the solid state. Angew. Chem., Int. Ed. 2002, 41 (1), 48-76.

(47) Jeffrey, G. A.; Jeffrey, G. A. An Introduction to Hydrogen Bonding; Oxford University Press: New York, 1997; Vol. 32.

(48) Dissegna, S.; Epp, K.; Heinz, W. R.; Kieslich, G.; Fischer, R. A. Defective Metal-Organic Frameworks. Adv. Mater. 2018, 30 (37), 1704501.

(49) Klet, R. C.; Liu, Y.; Wang, T. C.; Hupp, J. T.; Farha, O. K. Evaluation of Brønsted acidity and proton topology in $\mathrm{Zr}$ - and Hfbased metal-organic frameworks using potentiometric acid-base titration. J. Mater. Chem. A 2016, 4 (4), 1479-1485.

(50) Liu, Y.; Klet, R. C.; Hupp, J. T.; Farha, O. Probing the correlations between the defects in metal-organic frameworks and their catalytic activity by an epoxide ring-opening reaction. Chem. Commun. 2016, 52 (50), 7806-7809.

(51) Hajek, J.; Caratelli, C.; Demuynck, R.; De Wispelaere, K.; Vanduyfhuys, L.; Waroquier, M.; Van Speybroeck, V. On the intrinsic dynamic nature of the rigid UiO-66 metal-organic framework. Chem. Sci. 2018, 9 (10), 2723-2732.

(52) Caratelli, C.; Hajek, J.; Rogge, S. M. J.; Vandenbrande, S.; Meijer, E. J.; Waroquier, M.; Van Speybroeck, V. Influence of a Confined Methanol Solvent on the Reactivity of Active Sites in UiO66. ChemPhysChem 2018, 19 (4), 420-429.

(53) Ling, S.; Slater, B. Dynamic acidity in defective UiO-66. Chem. Sci. 2016, 7 (7), 4706-4712.
(54) Caratelli, C.; Hajek, J.; Cirujano, F. G.; Waroquier, M.; Llabrés i Xamena, F. X.; Van Speybroeck, V. Nature of active sites on UiO-66 and beneficial influence of water in the catalysis of Fischer esterification. J. Catal. 2017, 352, 401-414.

(55) Hajek, J.; Bueken, B.; Waroquier, M.; De Vos, D.; Van Speybroeck, V. The Remarkable Amphoteric Nature of Defective UiO-66 in Catalytic Reactions. ChemCatChem 2017, 9 (12), 22032210.

(56) Hajek, J.; Vandichel, M.; Van de Voorde, B.; Bueken, B.; De Vos, D.; Waroquier, M.; Van Speybroeck, V. Mechanistic studies of aldol condensations in UiO-66 and $\mathrm{UiO}-66-\mathrm{NH} 2$ metal organic frameworks. I. Catal. 2015, 331, 1-12.

(57) Yang, D.; Bernales, V.; Islamoglu, T.; Farha, O. K.; Hupp, J. T.; Cramer, C. J.; Gagliardi, L.; Gates, B. C. Tuning the Surface Chemistry of Metal Organic Framework Nodes: Proton Topology of the Metal-Oxide-Like Zr6 Nodes of UiO-66 and NU-1000. J. Am. Chem. Soc. 2016, 138 (46), 15189-15196.

(58) Driscoll, D. M.; Troya, D.; Usov, P. M.; Maynes, A. J.; Morris, A. J.; Morris, J. R. Characterization of Undercoordinated Zr Defect Sites in UiO-66 with Vibrational Spectroscopy of Adsorbed CO. J. Phys. Chem. C 2018, 122 (26), 14582-14589.

(59) Alaerts, L.; Seguin, E.; Poelman, H.; Thibault-Starzyk, F.; Jacobs, P. A.; De Vos, D. E. Probing the Lewis acidity and catalytic activity of the metal-organic framework [Cu3(btc)2] (BTC = benzene-1,3,5-tricarboxylate). Chem. - Eur. J. 2006, 12 (28), 7353-63.

(60) Stekrova, M.; Kumar, N.; Aho, A.; Sinev, I.; Grunert, W.; Dahl, J.; Roine, J.; Arzumanov, S. S.; Maki-Arvela, P.; Murzin, D. Y. Isomerization of alpha-pinene oxide using $\mathrm{Fe}$-supported catalysts: Selective synthesis of campholenic aldehyde. Appl. Catal., A 2014, $470,162-176$.

(61) Jiang, J.; Yaghi, O. M. Bronsted acidity in metal-organic frameworks. Chem. Rev. 2015, 115 (14), 6966-97.

(62) Morterra, C.; Cerrato, G.; Novarino, E.; Peñarroya Mentruit, M. On the Adsorption of Acetonitrile on Pure and Sulfated Tetragonal Zirconia (t-ZrO2). Langmuir 2003, 19 (14), 5708-5721.

(63) Ragon, F.; Campo, B.; Yang, Q.; Martineau, C.; Wiersum, A. D.; Lago, A.; Guillerm, V.; Hemsley, C.; Eubank, J. F.; Vishnuvarthan, M.; Taulelle, F.; Horcajada, P.; Vimont, A.; Llewellyn, P. L.; Daturi, M.; Devautour-Vinot, S.; Maurin, G.; Serre, C.; Devic, T.; Clet, G. Acid-functionalized UiO-66( $\mathrm{Zr})$ MOFs and their evolution after intraframework cross-linking: structural features and sorption properties. J. Mater. Chem. A 2015, 3 (7), 3294-3309.

(64) Yang, D.; Odoh, S. O.; Wang, T. C.; Farha, O. K.; Hupp, J. T.; Cramer, C. J.; Gagliardi, L.; Gates, B. C. Metal-Organic Framework Nodes as Nearly Ideal Supports for Molecular Catalysts: NU-1000and UiO-66-Supported Iridium Complexes. J. Am. Chem. Soc. 2015, 137 (23), 7391-7396.

(65) Yang, D.; Odoh, S. O.; Borycz, J.; Wang, T. C.; Farha, O. K.; Hupp, J. T.; Cramer, C. J.; Gagliardi, L.; Gates, B. C. Tuning Zr6Metal-Organic Framework (MOF) Nodes as Catalyst Supports: Site Densities and Electron-Donor Properties Influence Molecular Iridium Complexes as Ethylene Conversion Catalysts. ACS Catal. 2016, 6 (1), 235-247.

(66) Rasero-Almansa, A. M.; Iglesias, M.; Sánchez, F. Synthesis of bimetallic $\mathrm{Zr}(\mathrm{Ti})$-naphthalendicarboxylate MOFs and their properties as Lewis acid catalysis. RSC Adv. 2016, 6 (108), 106790-106797.

(67) Kaminska, J.; Schwegler, M.; Hoefnagel, A.; Van Bekkum, H. The isomerization of $\alpha$-pinene oxide with Brønsted and Lewis acids. Recl. Trav. Chim. Pays-Bas 1992, 111 (10), 432-437. 